\title{
Effect of Surface Texture and Humidity Environment on High Cycle Fatigue Property of Wrought Magnesium Alloys AZ31 and AZ61*
}

\author{
Toshifumi KAKIUCHI**, Yasuo OCHI***, Kenta TANAKA**** \\ and Takashi MATSUMURA*** \\ ** Department of Mechanical and Systems Engineering, Gifu University, \\ 1-1 Yanagido, Gifu, Gifu, 501-1193, Japan \\ E-mail: kakiuchi@gifu-u.ac.jp \\ *** Department of Mechanical Engineering and Intelligent Systems, The University of \\ Electro-Communications, \\ 1-5-1 Chofugaoka, Chofu, Tokyo, 182-8585, Japan \\ **** Yokogawa Electric Corporation, \\ 2-9-32 Nakacho, Musashino, Tokyo, 180-8750, Japan
}

\begin{abstract}
Rotating bending fatigue tests on AZ31 and AZ61 wrought magnesium alloys were carried out in order to investigate the effects of specimen surface texture and the humidity environment of experiment. Specimen surface texture was varied by using an emery paper of a different roughness or by buff polishing to mirrored surface in final finish of specimen surface treatment. The conditions of environment in which fatigue tests were conducted were the laboratory's air, the dry air, the humid air and the water. As a result, the fatigue life of a specimen with a rough surface was shorter than that with a smooth surface. But the fatigue life of a specimen with mirrored surface was shorter than that with a little rougher surface by an emery polishing. It is attributed to that the effect of work-hardened layer on the fatigue life exists. And then the fatigue life is predicted by the Varea parameter model in which a depth of surface roughness is regarded as a size of defect. The effect of surface roughness was more apparent in the case that a specimen is polished in the circumferential direction which is parallel to the crack propagation direction compared with the case that a specimen is polished in the axial direction. The fatigue strength in the region of a long fatigue life in water was smaller than that in the other environments; however this feature is not so apparent in the region of the short life. Except for in the water environment, the fatigue life became shorter in the descending order of the dry air, the laboratory's air and the humid air.
\end{abstract}

Key words: High Cycle Fatigue, Magnesium Alloys, Surface Texture, Roughness, Humidity Environment

\section{Introduction}

Magnesium is the lowest in density among all practical metals and is superior in specific strength and rigidity. It has good properties in electromagnetic shielding, vibration suppression and impact absorption. So magnesium alloys are used for mobile electronic devices and notebook computers. ${ }^{(1)}$ In addition, it is abundant as resource and so the further use of magnesium alloys as a general structural material is expected in the near future. In recent years, from the viewpoint of the environmental conservation, lightening the structural 
material for the transportation machinery such as automobiles has been advanced to improve fuel consumption and magnesium alloys are strongly expected for this usage.

To use the alloys for machine structures for a long term, the research on the fatigue strength is indispensable; however that of magnesium alloys is not necessarily enough since the history of magnesium alloys as a structural material is not so long compared with the other light metals. Especially for practical use, the influence of the surface texture and the humidity environment on the fatigue property of the materials is important. For example of the past studies on the effect of the surface texture on the fatigue property of magnesium alloys, the effect of notch sensitivity on the fatigue crack initiation was studied by Kusukawa et al. ${ }^{(2)}$ The effect of the humidity environment was also studied by Kusukawa et al. ${ }^{(3)}$ and by Hanaki et al. ${ }^{(4)}$ In the present study, the rotating bending fatigue tests were performed using specimens of the wrought magnesium alloys AZ31 and AZ61 with different surface finishes in the 4 kinds of humidity environment, and the fatigue property of the materials over $10^{7}$ cycles and the influence of the surface texture and the humidity environment on the fatigue property were investigated.

\section{Experiment}

\subsection{Material}

The test materials are AZ31 and AZ61 rolled magnesium alloys. Test specimens are made from the extruded round bar of which the diameter is $16 \mathrm{~mm}$. AZ61 specimens are taken from two different lots and are denoted as AZ61(L1) and AZ61(L2) respectively. Table 1 shows the chemical compositions of the materials and the mechanical properties are shown in Table 2. From the microstructure observation, there is no anisotropy depending on the extrusion direction and the average grain size of AZ31 measured according to JIS G0551 is about $100 \mu \mathrm{m}$ and that of AZ61(L1) and AZ61(L2) are about $18 \mu \mathrm{m}$.

\subsection{Experimental procedure}

The fatigue test was conducted on an Ono-type rotating bending fatigue test machine having a rotational speed of $2760 \mathrm{rpm}$ with a stress ratio $\mathrm{R}=-1$.

All specimens were made by machining in shape as shown in Fig.1. Then a center of AZ31 and AZ61(L1) specimens was polished using emery papers up to of \#2000, and that of AZ61(L2) specimens was polished using emery papers up to of \#1500. These specimens are denoted as "2000" and "1500". In addition to that, some specimens were polished again using an emery paper of $\# \mathrm{X}$, which is denoted as " $\mathrm{X}$ ", and some other specimens were polished again to mirror finish using emery papers up to \#2000 followed by buffing using aluminum solution, which is denoted as "Mirrored". A specimen which is polished in the axial direction is denoted as " $\mathrm{A}$ " and that polished in the circumferential direction is

Table 1 Chemical composition of magnesium materials [mass \%].

\begin{tabular}{cccccccccc}
\hline & $\mathrm{Al}$ & $\mathrm{Zn}$ & $\mathrm{Mn}$ & $\mathrm{Fe}$ & $\mathrm{Si}$ & $\mathrm{Cu}$ & $\mathrm{Ni}$ & $\mathrm{Ca}$ & $\mathrm{Mg}$ \\
\hline \hline $\mathrm{AZ31}$ & 2.96 & 0.79 & 0.39 & 0.003 & 0.004 & 0.0019 & 0.0001 & 0.0039 & Bal. \\
\hline AZ61(L1) & 6.04 & 0.62 & 0.25 & 0.005 & 0.011 & 0.0013 & 0.0007 & - & Bal. \\
\hline AZ61(L2) & 6.04 & 0.67 & 0.34 & 0.004 & 0.006 & 0.0007 & 0.0003 & - & Bal. \\
\hline
\end{tabular}

Table 2 Mechanical properties of magnesium materials.

\begin{tabular}{ccccc}
\hline & $\begin{array}{c}\text { Tensile strength } \\
{[\mathrm{MPa}]}\end{array}$ & $\begin{array}{c}0.2 \% \text { Proof stress } \\
{[\mathrm{MPa}]}\end{array}$ & $\begin{array}{c}\text { Elongation } \\
{[\%]}\end{array}$ & $\begin{array}{c}\text { Vickers hardness } \\
{[\mathrm{HV}]}\end{array}$ \\
\hline $\mathrm{AZZ31}$ & 262 & 210 & 17.8 & 52 \\
\hline AZ61(L1) & 304 & 222 & 18.1 & 62 \\
\hline AZ61(L2) & 299 & 210 & 19.3 & 61 \\
\hline
\end{tabular}




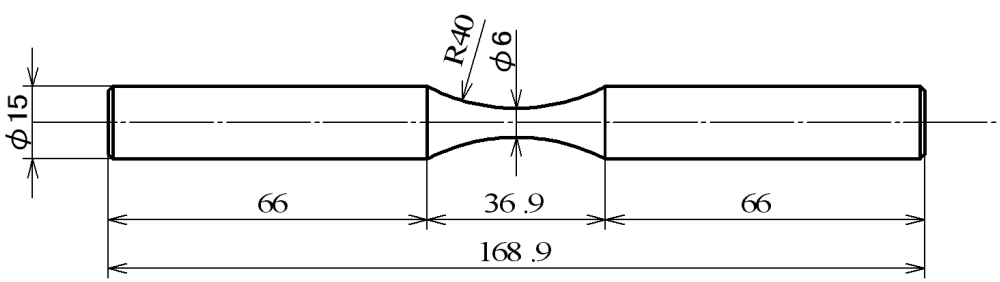

Fig.1 Shape of specimen [mm].

denoted as "C".

The test environments were 4 kinds; the laboratory room atmospheric environment, the dry environment, the high humidity environment and the water dropped environment. In the dry environment test, dry air is obtained by an air compressor equipped with a film type drier and is sprayed directly on a test specimen. A small acrylic chamber is equipped around a test specimen so that the environment is not influenced by the laboratory atmosphere if possible. The relative humidity in the chamber of the dry environment was $10 \%$ or less. In the high humidity environment test, high humidity air is obtained by using the vaporizing humidifier and is sent to a small acrylic chamber in which a test specimen is set. The relative humidity in the chamber of the high humidity environment was $85 \% \pm 10 \%$. In the water dropped environment, the ion-exchanged water is dropped directly to a test specimen at a rate of $0.5 \mathrm{~L} / \mathrm{min}$. The fatigue test in the laboratory room atmospheric environment is conducted on all kinds of the specimens. In the test in the water dropped environment, 3 kinds of specimens; AZ31-2000-A, AZ61(L1)-2000-A and AZ61(L2)-Mirrored-C; are used. In the dry environment and in the high humidity environment the AZ61(L2)-Mirrored-C specimen is used.

The fracture surface of a test specimen after the fatigue test is observed under a scanning electron microscope (SEM).

\section{Experimental results}

\subsection{Fatigue test results}

Figure 2 shows the fatigue test results in the laboratory room atmospheric environment. A plot point with a symbol of $*$ is a result in which plural crack initiation sites were observed. The S-N curve shows a step-wise shape, which bends horizontally at around $10^{5}$ cycles and bends downward again after $10^{7}$ cycles.

In the comparison between the Mirrored-C and the 2000-A specimens of AZ31 and AZ61(L1) respectively, the fatigue life of the Mirrored-C, of which the surface roughness is smaller, was shorter than that of the 2000-A in the slope of the S-N curve before $10^{5}$ cycles. This tendency that the fatigue life of the Mirrored-C is shorter in the slope is more apparent in the comparison of the Mirrored-C with the 1500-A specimens of AZ61(L2).

In the comparison between the "A" specimens of AZ31 and AZ61(L1), which are polished in the axial direction, finished by a different kind of an emery paper respectively, the scatter of the test results is wide and the difference by the emery paper kind is small. However the "C" specimens of AZ61(L2), which are polished in the circumferential direction, the tendency is clearly admitted that the fatigue life of a specimen with a large surface roughness was short. This is considered to be attributed to that the crack propagation direction is the circumferential direction of a test specimen. So in the "A" specimen, in which the polish direction is perpendicular to the crack propagation direction, an initiation and a propagation of a crack is suppressed; however in the " $C$ " specimen, in which they are parallel, the effect of the surface roughness appeared easily.

Figure 3 shows the other humidity environments' test results. The results of the 
laboratory room atmospheric environment test are plotted with them to be compared.

The bending point is not admitted in the S-N curve of the test results in the water dropped environment and the fatigue limit does not appear; however the fatigue strengths in

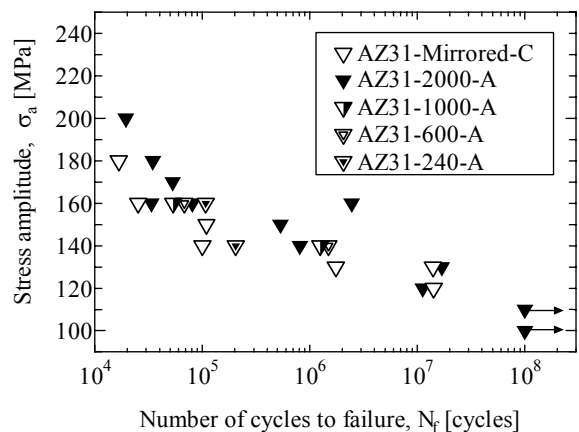

(a) AZ31

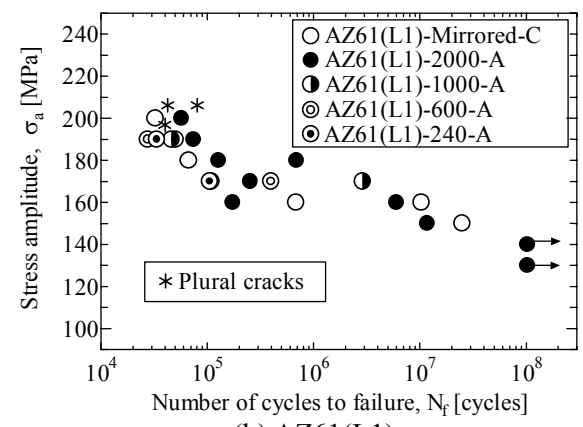

(b) AZ61(L1)

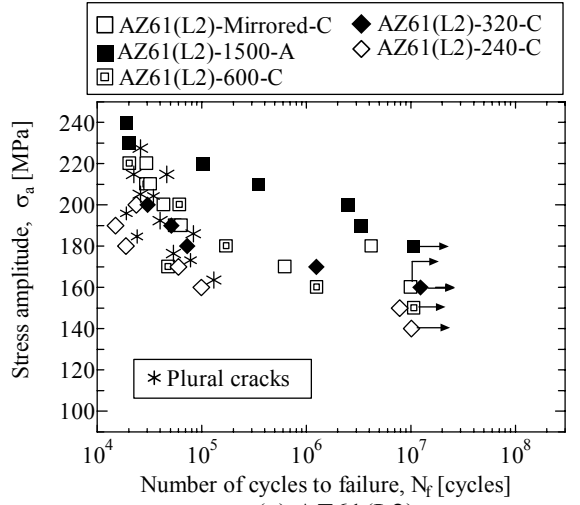

(c) AZ61(L2)

Fig.2 S-N diagrams of fatigue test in laboratory air.

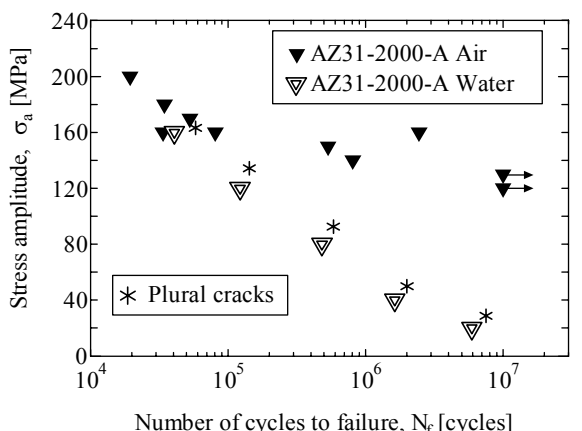

(a) AZ31

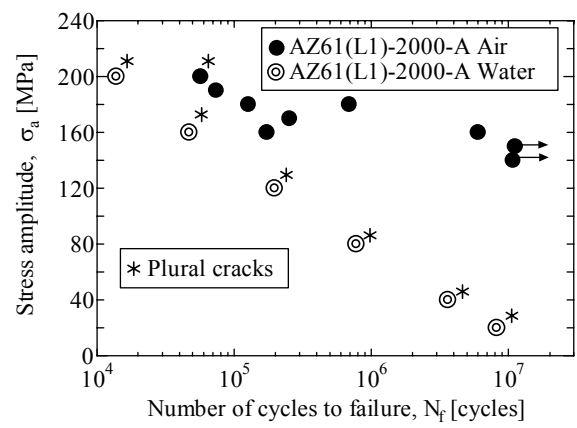

(b) AZ61(L1)

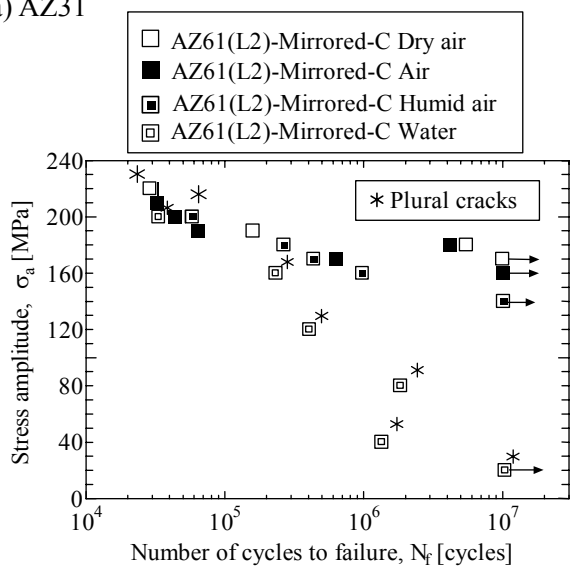

(c) AZ61(L2)

Fig.3 S-N diagrams of fatigue test in humidity environment. 
the water dropped environment and the laboratory air environment are not so different in the region of the short fatigue life. This is attributed to that in the region of the short fatigue life, the time in which a test specimen is exposed to the water and the effect of corrosion is not apparent.

The fatigue strengths at $10^{7}$ cycles in the other environments except for the water dropped environment are $160 \mathrm{MPa}$ in the laboratory room atmospheric environment, 170 $\mathrm{MPa}$ in the dry environment and $140 \mathrm{MPa}$ in the high humidity environment. The fatigue strength becomes large as the relative humidity of the environment becomes low; however the difference is not so apparent compared with the effect of the water dropped environment.

\subsection{Fracture surface observation}

The fracture surface was observed by an SEM to investigate the fracture initiation site and the fracture morphology.

A corrosion pit was not observed on or around a fracture surface of all fractured specimens in the laboratory room atmospheric environment. All of the fracture initiation sites were on the surface of a specimen. In most of the fracture surfaces an initiation site was single; however in some of the fracture surfaces, initiation sites were plural. As the stress amplitude is larger, it becomes easier that fracture initiation sites are plural. This tendency is particularly apparent on the AZ61(L2)-C specimen.

Figure 4 shows the SEM observation results of the fracture surfaces of " 2000 " and " $1500 "$ specimens in the laboratory room atmospheric environment. On the fracture surface of the AZ31-2000-A specimen, a stripe pattern is formed from the crack initiation site and the roughness becomes larger apart from the crack initiation site. On the other hand, on the fracture surface of the AZ61(L1)-2000-A and AZ61(L2)-1500-A specimens, the roughness is large at the crack initiation site and it becomes small apart from the crack initiation site. A large difference was not observed in the comparison between the fracture surfaces of the different level in the stress amplitude and the fatigue life.

The difference dependent on the emery paper kind, which was used in a final finish of a specimen surface treatment, was not observed apparently in the fracture surface of the " $A$ " specimens of AZ31 and AZ61(L1). Figure 5 shows the SEM observation results of the fracture surfaces of different surface textures of the AZ61(L2)-C specimens. The steps were

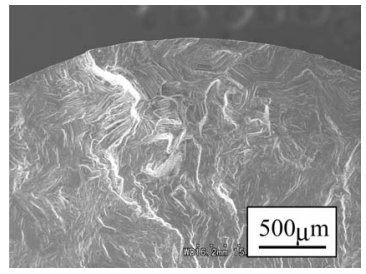

(a) AZ31-2000-A $\sigma_{\mathrm{a}}=120 \mathrm{MPa}, \mathrm{N}_{\mathrm{f}}=1.1 \times 10^{7}$ cycles

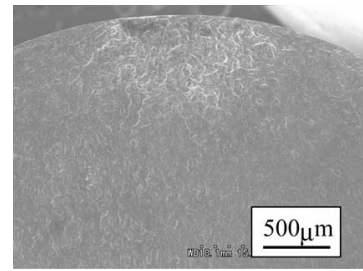

(b) AZ61(L1)-2000-A $\sigma_{\mathrm{a}}=150 \mathrm{MPa}, \mathrm{N}_{\mathrm{f}}=1.2 \times 10^{7}$ cycles

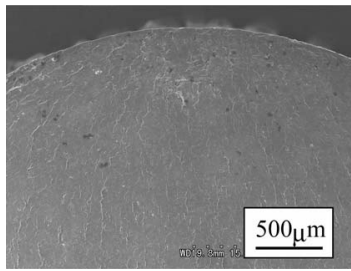

(c) AZ61(L2)-1500-A $\sigma_{\mathrm{a}}=190 \mathrm{MPa}, \mathrm{N}_{\mathrm{f}}=3.4 \times 10^{6}$ cycles

Fig.4 SEM micrographs of fracture surfaces of different materials in laboratory air.

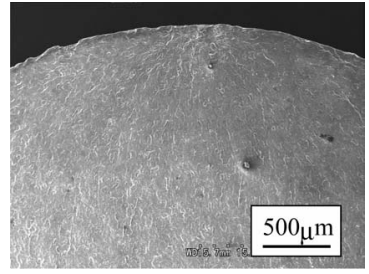

(a) AZ61(L2)-Mirrored-C $\sigma_{\mathrm{a}}=200 \mathrm{MPa}, \mathrm{N}_{\mathrm{f}}=4.3 \times 10^{4}$ cycles

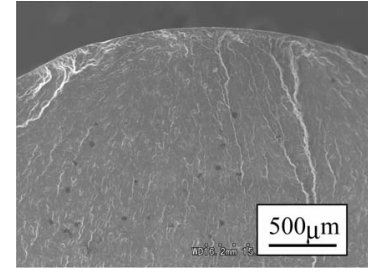

(b) AZ61(L2)-600-C $\sigma_{\mathrm{a}}=210 \mathrm{MPa}, \mathrm{N}_{\mathrm{f}}=2.9 \times 10^{4}$ cycles

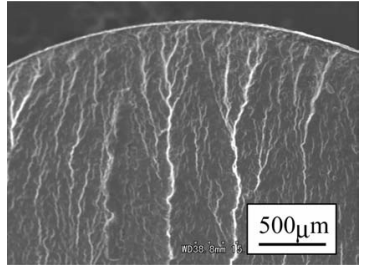

(c) AZ61(L2)-240-C $\sigma_{\mathrm{a}}=180 \mathrm{MPa}, \mathrm{N}_{\mathrm{f}}=1.9 \times 10^{4}$ cycles

Fig.5 SEM micrographs of fracture surfaces of AZ61(L2) of different surface finish in laboratory air. 


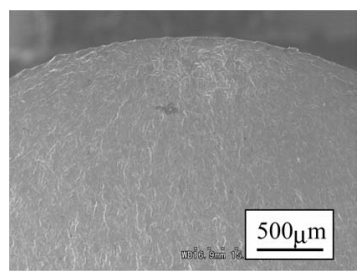

(a) AZ61(L2)-Mirrored-C

Dry air, $\sigma_{\mathrm{a}}=180 \mathrm{MPa}, \mathrm{N}_{\mathrm{f}}=5.5 \times 10^{6}$ cycles

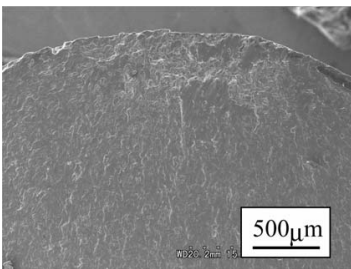

(b) AZ61(L2)-Mirrored-C Humid air, $\sigma_{\mathrm{a}}=170 \mathrm{MPa}, \mathrm{N}_{\mathrm{f}}=4.4 \times 10^{5}$ cycles

Fig.6 SEM micrographs of fracture surfaces of AZ61(L2)-Mirrored-C in different humidity environment.

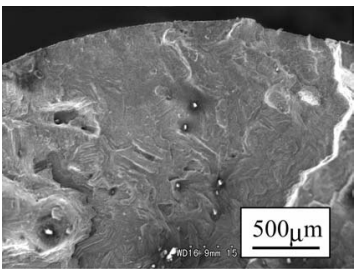

(a) AZ31-2000-A $\sigma_{\mathrm{a}}=80 \mathrm{MPa}, \mathrm{N}_{\mathrm{f}}=4.8 \times 10^{5}$ cycles

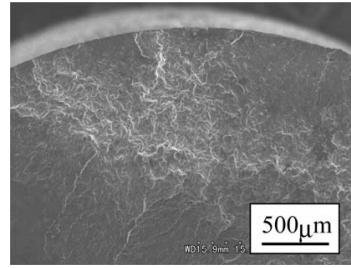

(b) AZ61(L1)-2000-A $\sigma_{\mathrm{a}}=80 \mathrm{MPa}, \mathrm{N}_{\mathrm{f}}=7.7 \times 10^{5}$ cycles

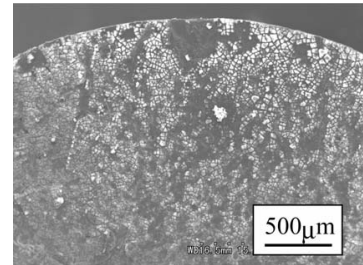

(c) AZ61(L2)-Mirrored-C $\sigma_{\mathrm{a}}=80 \mathrm{MPa}, \mathrm{N}_{\mathrm{f}}=1.8 \times 10^{6}$ cycles

Fig.7 SEM micrographs of fracture surfaces in water dropped environment.

observed in the radius direction of a specimen in the fracture surface of the 600-C and 240-C specimens, which were not observed in the fracture surfaces of the Mirrored-C specimen. The steps were particularly apparent in the $240-\mathrm{C}$ specimen.

Figures 6 shows the SEM observation results of the fracture surfaces of the AZ61(L2)-Mirrored-C specimens in the dry environment and the high humidity environment. Figure 7 shows that of the AZ31-2000-A, the AZ61(L1)-2000-A and the AZ61(L2)-1500-A specimens in the water dropped environment.

A large difference is not admitted between the fracture surfaces in the dry environment and the high humidity environment compared with that in the laboratory room atmospheric environment. On the fracture surfaces of AZ31 in the water dropped environment, a stripe pattern which was observed in the other environments was not observed. In the water dropped environment, the roughness at the crack initiation site of the fracture surface of AZ61(L1) and AZ61(L2) was flat and on AZ61(L2) small tegular cracks were observed.

It is reported that the fatigue properties of magnesium alloys are influenced by the inclusion. ${ }^{(5),(6)}$ In the present study, the chemical composition around the crack initiation sites was analyzed using an EPMA (Electron Probe Micro Analyzer); however an inclusion was not observed.

\section{Discussion}

\subsection{Effect of work hardened layer}

From the fatigue test results, it is confirmed that the " 1500 " and " $2000 "$ specimens have longer fatigue lives than the Mirrored specimens of which the specimen surface is smoother than that of the " $1500 "$ and "2000" specimens. This is considered because the polishing amount of the Mirrored specimen is large since they are polished again with emery papers from of the small number to erase the polishing flaws and so the amount of the removal in the hardened layer by the machining process is also large. So the Vickers hardness test was conducted on the " 1500 " and "2000" specimens to investigate the effect of the work hardened layer on the fatigue test results. Figure 8 shows the results of the hardness test. In all test specimens, the work hardening of about $15 \mathrm{HV}$ increased was observed near the surface compared with the inside, which is considered to be caused by the machining 


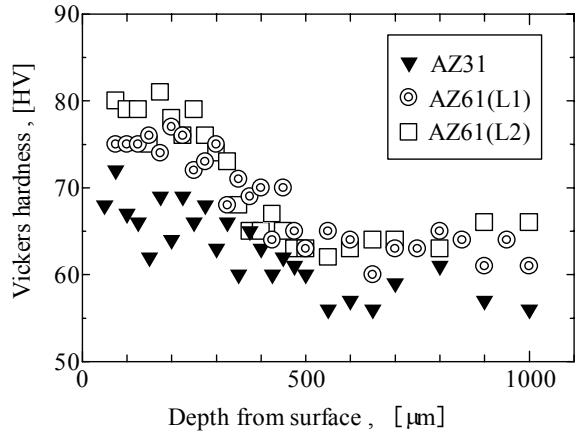

Fig.8 Hardness distribution.

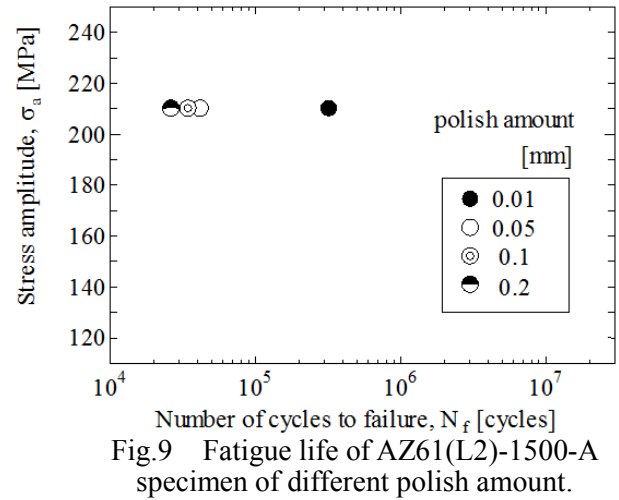

process. The depth of the hardened layer is about $500 \mu \mathrm{m}$ in all specimens. Then using the AZ61(L2) specimen of which the fatigue life of the Mirrored specimen was remarkably shorter compared with the "1500" specimen, fatigue tests were conducted on the specimens of a different amount of polishing in order to investigate whether the hardened layer, which is observed in the range from the surface to the depth of $500 \mu \mathrm{m}$ by the Vickers hardness test, affected the fatigue life. The finish of the surface treatment was polishing by an emery paper of \#1500 in the axial direction. Figure 9 shows the results. The fatigue life became short in a specimen of large amount of polishing; however the fatigue life of a specimen of which the polish amount was $50 \mu \mathrm{m}$ or more was not shortened any more. From these results, it is confirmed that on the magnesium alloys used in this study, the effect of the factors of the hardened layer in the range from the surface to the depth of $50 \mu \mathrm{m}$ on the increase of fatigue life was large, but the increased hardness does not contribute to the effect and what contributes to this effect, which may be residual stress or other factors, was not clarified well.

\subsection{Evaluation of surface roughness}

From the fatigue test results, the effect of the number of an emery paper used in the finish of the specimen surface treatment was confirmed and the fatigue limits are distinguished significantly. To evaluate the effect, the roughness is measured. Table 3 shows the roughness test results. It is confirmed that the surface roughness increases as the number of an emery paper decreases. For the quantitative evaluation of the effect of the surface roughness on the fatigue life, the fatigue limit estimation of the AZ61(L2)-C specimen, of which the effect of the number of an emery paper on the fatigue life is large, is attempted using the Varea parameter model in which a surface roughness is regarded as a defect ${ }^{(7)}$, used in the study of Itoga et al. ${ }^{(8)}$

In case that the fracture initiation site is on the surface, the fatigue limit is estimated by Eq.(1).

$$
\sigma_{w p}=\frac{1.43(H V+120)[(1-R) / 2]^{\alpha}}{(\sqrt{\text { area }})^{1 / 6}}
$$

where $\sigma_{w p}$ : estimated fatigue limit $(\mathrm{MPa}), H V$ : Vickers hardness $\left(\mathrm{kgf} / \mathrm{mm}^{2}\right), R$ : stress ratio and $\alpha: 0.226+H V \times 10^{-4}$. Varea is calculated by Eqs.(2) and (3) as a size of an equivalent defect.

$$
\begin{aligned}
& \frac{\sqrt{\text { area }}}{2 b}=2.97\left(\frac{a}{2 b}\right)-3.51\left(\frac{a}{2 b}\right)^{2}-9.74\left(\frac{a}{2 b}\right)^{3} \text { for } \frac{a}{2 b}<0.195 \\
& \frac{\sqrt{\text { area }}}{2 b} \cong 0.38 \text { for } \frac{a}{2 b}>0.195
\end{aligned}
$$

where $a$ : depth of a surface roughness and $2 b$ : pitch of a surface roughness. For the value of $a$, an average roughness Ra or a maximum roughness depth Ry is used. The pitch $2 b$ is defined as the distance along the specimen surface between the top of the roughness curve to the next top, which is calculated as the total measured roughness curve distance divided 
Table 3 Surface roughness of AZ61.

\begin{tabular}{c||cc}
\hline & $\mathrm{Ra}[\mu \mathrm{m}]$ & $\mathrm{Ry}[\mu \mathrm{m}]$ \\
\hline \hline Mirrored-C & 0.18 & 1.3 \\
$600-\mathrm{C}$ & 0.49 & 3.7 \\
$320-\mathrm{C}$ & 1.03 & 7.6 \\
$240-\mathrm{C}$ & 1.85 & 12.4 \\
$2000-\mathrm{A}$ & 0.25 & 1.9 \\
$1500-\mathrm{A}$ & 0.24 & 2.1 \\
$1000-\mathrm{A}$ & 0.24 & 2.2 \\
$600-\mathrm{A}$ & 0.44 & 3.4 \\
$240-\mathrm{A}$ & 1.34 & 10.2 \\
\hline
\end{tabular}

Table 5 Fatigue limit predicted by Ry parameter.

\begin{tabular}{c||c|c|c}
\hline Specimen & Ry $[\mu \mathrm{m}]$ & $\begin{array}{c}\text { Predicted } \\
\text { fatigue limit[MPa }]\end{array}$ & $\begin{array}{c}\text { Experimental } \\
\text { fatigue limit[MPa }]\end{array}$ \\
\hline \hline AZ61(L2)-Mirrored-C & 1.3 & 208 & 160 \\
AZ61(L2)-600-C & 3.7 & 176 & 150 \\
AZ61(L2)-320-C & 7.6 & 159 & 160 \\
AZ61(L2)-240-C & 12.4 & 151 & 140 \\
\hline
\end{tabular}

by number of tops.

Tables 4 and 5 show the predicted fatigue limits of the "C" specimens, which are polished in the circumferential direction, compared with that of the actual test results. Here it is noted that as discussed in the above, the layer which affects the fatigue life is assumed to be removed in the polished specimen and so in the fatigue limit prediction, the effect of residual stress or other factors, which may affect the fatigue life, is not considered. The predicted fatigue limit calculated using Ry for " $a$ " corresponds well with that of the test results. Especially the prediction of the $600-\mathrm{C}, 320-\mathrm{C}$ and $240-\mathrm{C}$ specimens, of which the roughness is comparatively large and Ry is over about $4 \mu \mathrm{m}$, is good. On the other hand, the precision of the prediction is not so good for the Mirrored-C specimen. This is attributed to that the roughness of which Ry is $1.3 \mu \mathrm{m}$ cannot be regarded as a defect since it is too small. From this, it is confirmed that the Varea parameter model which evaluates the fatigue limit regarding the surface roughness as a defect is effective for the prediction of the fatigue limit of the magnesium alloys. The precision of the fatigue limit estimation using Ry is good compared with that using $\mathrm{Ra}$. This is attributed to that the role of the surface roughness as a defect is effective at the site of the maximum height of roughness.

\subsection{Effect of humidity environment}

From the fatigue test results, the effect of the environment on the fatigue life is apparent. To investigate the effect in detail, the crack propagation behavior of the AZ61(L2)-Mirrored-C specimen was observed using the replication technique. Figure 10 shows the crack propagation curve. The ratio of the number of cycles where a crack initiation is observed to that of the fracture of a specimen becomes smaller in the

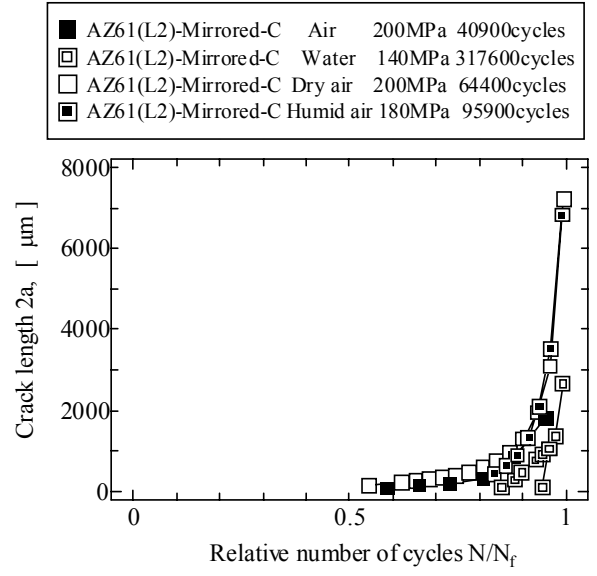

Fig.10 Relations between crack length and relative number of cycles.

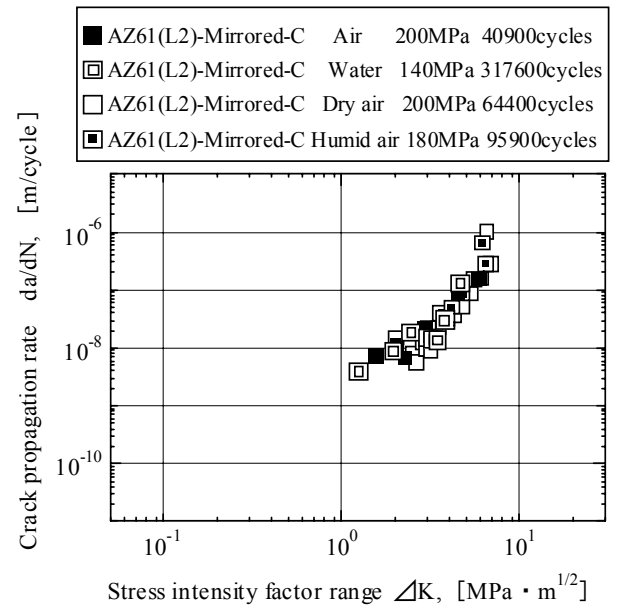

Fig.11 Relations between crack propagation rate and stress intensity factor range. 


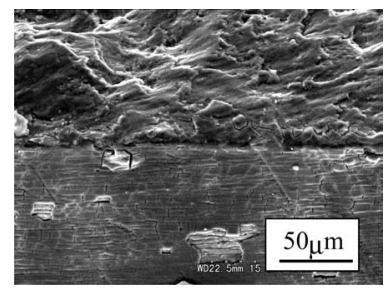

Fig.12 SEM micrograph of fracture surface and specimen surface of AZ61(L2)-Mirrored-C.

(Water, $\sigma_{\mathrm{a}}=140 \mathrm{MPa}, \mathrm{N}_{\mathrm{f}}=3.2 \times 10^{5}$ cycles)

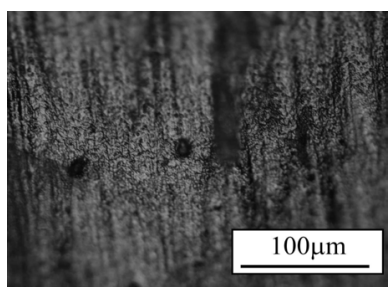

Fig.13 SEM micrograph of specimen surface of AZ61(L2)-Mirrored-C.

(Water, $\sigma_{\mathrm{a}}=20 \mathrm{MPa}, \mathrm{N}_{\mathrm{f}}=1.0 \times 10^{7}$ cycles)

descending order of the dry environment, the laboratory room atmospheric environment, the high humidity environment and the water dropped environment. Figure 11 shows the relationship between the crack propagation rate $\mathrm{da} / \mathrm{dN}$ and the stress intensity factor range $\Delta K$. For the caflculation of $\Delta K$, the equation shown in the handbook ${ }^{(9)}$ with aspect ratio of 1 is used. The crack propagation rate becomes faster in the same order with the above; however the difference of the rate between the environments is small. Here it is noted that the crack propagation rate in the water dropped environment scatters in a wide range is because the crack length increases largely when plural cracks coalescence with each other.

The effect of the water dropped environment on the fatigue test results is large especially in the range where the stress is low and the life is long. And the further observation was conducted on the fractured specimen of the water dropped environment. Figure 12 shows the SEM observation results in which the fracture surface and the specimen surface were observed together. On the specimen surface of the laboratory room atmospheric environment, nothing particular was observed; however on that of the water dropped environment, many small cleavages were observed. By a further investigation in detail on the specimen surface of the water dropped environment, corrosion pits were observed as shown in Fig.13. In magnesium alloys in the corrosive environment, a brittle passivation film such as $\mathrm{Mg}(\mathrm{OH})_{2}$ or $\mathrm{MgO}$ is formed on a surface. It is considered that small cleavages occur in the film subjected to the cyclic loading and corrosion pits are generated. From the corrosion pits, cracks initiate and propagate to the fracture of a specimen. It is considered to attribute to that a clear fatigue limit does not exist.

\section{Conclusion}

Rotating bending fatigue tests on wrought magnesium alloys AZ31 and AZ61 were conducted to investigate the effects of the specimen surface texture of a different roughness and the environment of a different relative humidity. and the following conclusions are derived.

(1) The fatigue life became short as the surface roughness increases. This tendency appeared more remarkably when the polish direction and the crack propagation direction were parallel than when they were vertical. The fatigue life became short also when the removal amount of the specimen surface hardened layer by machining process increases. Especially the influence of the hardened layer from the surface to the depth of $50 \mu \mathrm{m}$ was large.

(2) On the fracture surface of AZ31, a stripe pattern was formed from the crack initiation site. The roughness was small at the crack initiation site and it became larger apart from the crack initiation site. On the fracture surface of AZ61, the roughness was large at the crack initiation site and it became smaller apart from the crack initiation site.

(3) The fatigue limit of AZ61(L2)-C specimen was evaluated using the $\sqrt{\text { area }}$ parameter model in which a surface roughness is regarded as a defect. The estimated fatigue limit calculated using the maximum roughness depth Ry corresponds well with that of the test results; however the precision of the estimation of the Mirrored specimen, of which the 
surface roughness is small, was not so good.

(4) The fatigue limit became shorter in the descending order of the dry environment, the laboratory room atmospheric environment, the high humidity environment and the water dropped environment. The crack propagation rate becomes larger in the same order with the above; however the difference of the crack propagation rate is small. The descent of the fatigue strength is apparent in the water dropped environment and a clear fatigue limit does not exist.

\section{Acknowledgement}

This study was supported through the standardization research project by New Energy and Industrial Technology Development Organization (NEDO).

\section{References}

(1) The Japan Society for Technology of Plasticity ed., Magnesium Processing technology (in Japanese), (2004), Corona Publishing.

(2) Kusukawa, K. and Takao, K., Fatigue Crack Initiation Behavior and Notch Sensitivity of AZ92A Magnesium Alloy, Transactions of the Japan Society of Mechanical Engineers, Series A, Vol.68, No.671 (2002), pp.1092-1097.

(3) Kusukawa, K. and Takao, K., Effect of Water Environment on Fatigue Behaviors of Magnesium Alloys, Transactions of the Japan Society of Mechanical Engineers, Series A, Vol.72, No.723 (2006), pp.1737-1743.

(4) Hanaki, S., Goto, H., Yamashita, M. and Uchida, H., Reliability Evaluation of Fatigue Characteristics of Magnesium Alloy AZ31B under Corrosive Environment, Journal of the Society of Materials Science, Japan, Vol.55, No.11 (2006), pp.1011-1015.

(5) Sajuri, Z.B., Miyashita, Y. and Mutoh, Y., Fatigue Characteristics of an Extruded AZ61 Magnesium Alloy, Journal of Japan Institute of Light Metals, Vol.52, No.4 (2002), pp.161-166.

(6) Kitahara, Y., Ikeda, K., Shimazaki, H., Noguchi, H., Sakamoto, M. and Ueno, H., Fatigue Strength Characteristics of Non-Combustible Mg Alloy (1st Report, Quantitative Comparison among Fatigue Strengths of Three Non-Combustible Mg Alloys), Transactions of the Japan Society of Mechanical Engineers, Series A, Vol.72, No.717 (2006), pp.661-668.

(7) Murakami, Y., Takahashi, K. and Yamashita, T., Quantitative Evaluation of the Effect of Surface Roughness on Fatigue Strength (Effect of Depth and Pitch of Roughness), Transactions of the Japan Society of Mechanical Engineers, Series A, Vol.63, No.612 (1997), pp.1612-1619.

(8) Itoga, H., Tokaji, K., Nakajima, M. and Ko, H.-N., Effects of Notch and Surface Roughness on Long Life Fatigue Behaviour in High Strength Steels, Journal of the Society of Materials Science, Japan, Vol.54, No.12 (2005), pp.1249-1254.

(9) The Society of Materials Science, Japan ed., Stress Intensity Factors Handbook, Vol.2 (1987), pp.657-665, Pergamon Press. 